\title{
THE NEUROSCIENCE ASPECTS OF ADOLESCENT BEHAVIOUR AND ITS IMPLICATIONS
}

\author{
Ms. Kamal Gulati Manwani \\ Ph.D. Scholar \\ Amity Institute of Education, AUUP \\ Mobile no: 9818123678 \\ Email ID: kamal.gulati@student.amity.edu \\ Dr. Mahima Gupta \\ Associate Professor \\ Amity Institute of Education, AUUP \\ Mobile no: 9999010736 \\ Email ID: mgupta2@amity.edu
}

\begin{abstract}
Education is considered to be a tool for providing knowledge, building character and promising a comfortable lifeto its learners. To ensure desired learning outcomes, a lot is being done in the areas of developing better curriculum, making state of the art institutions, improving teacher quality, providing digital platforms, enhancing parental involvement etc. However, when it comes to designing Pedagogical Tools based on the learning patterns of the brain, there is seen a wide gap between what is researched in laboratories and what is witnessed in our classrooms. Pedagogical practices not based on an understanding of how a learner's brain works and what are its needs can lead to undesired behavioural consequences in them. This becomes more pronounced as learners enter into adolescence, a period in development marked with rapid changes at mental, physical, emotional and psychological levels.

This paper looks into various researches that have been done in Cognitive Neuroscience and their educational implications on adolescent learners. It explores why educational practices must take into consideration the cognitive aspects of an adolescent's brain like role of reward system, enhancing Working Memory, providing multisensory stimulus, using memory strategies, understanding learner behavior and needs etc. This paper concludes by providing insights on how learnings from these Neuroscience researches can address the issue of high risk behaviour tendencies and mental disorders amongst adolescent learners.
\end{abstract}

KEYWORDS: Adolescent learners, Cognitive Neuroscience Research, Pedagogical practices, Adolescent high risk behaviour

Article Received: 10 August 2020, Revised: 25 October 2020, Accepted: 18 November 2020

\section{INTRODUCTION}

Today's times demand a paradigm shift in how we view education. Education needs to exit the image of being just a tool for providing knowledge, building character and promising a comfortable life and take onchallenging roles to meet with the risks modernization poses. In view of this, numerous policy frameworks are made from time to time to ensure education lays a foundation of an empowered life for its learners. Learning is now equipped with technological support and breakthrough pedagogies to help learners achieve not only academic excellence but also the life skills to cope with various life situation. However, while designing educational programs and breakthrough pedagogies, little attention is paid to linking them with learning styles of a learner's brain. This becomes a greater challenge as the learners grow in age. Onset of adolescence causes major changes in brain and its functioning to happen. This potentially can lead to a mismatch between pedagogical styles and learning patterns of an adolescent learner's brain. There has been extensive Cognitive Neuroscience research in the last few decadesto understand the working of human brain. Unfortunately, the findings of these researches hardly enter classrooms from laboratories. The chief aim of education should be to enable learners to effectively utilize the vast capacity of their brains but sadly academic load is seen to be narrowing down the brain's utilization to curricular tasks. Irrelevant teaching practices and content can lead to cognitive overload in learners causing undesired behavioural consequences in them, especially in adolescent learnersat times leading to High Risk Behavior tendencies also. The failure of optimal decision making regions in brain can lead to impulsive behaviors (Soyoun Kim, Daeyeol Lee). 
This paper, through various articles on brain-based researches and secondary data, looks into the learning styles of an Adolescent's brain and its implications on education. It advocates the importance of understanding the working of human brain before designing pedagogy and also suggests various steps that can be taken in this direction.

This paper is a study based on secondary data from various research articles in journals, websites and books on Cognitive Neuroscience research and Adolescent behavior and their educational implications.

\section{PROCESSING IN HUMAN BRAIN}

Information is gathered by human brain throughsensory perceptions into a space of limited memory called as Working Memory. Working memory can hold limited information at one time and sends relevant information to long term memory of infinite capacity in brain capacity for later retrieval. This Working Memory facilitates planning, comprehension, reasoning, and problemsolving (Cowan, 2014).Itleads to the activation ofan area in brain called as Prefrontal Cortex. This prefrontal cortex is responsible for reasoning, judgment, setting goals, analysis of consequences, higher order thinking and other executive functions.

\section{PREFRONTAL CORTEX AND ITS ROLE}

Prefrontal Cortex $\mathrm{s}$ a region in brain that is responsible for executive functions like attention, focusing attention, understanding the consequences of ones actions, emotional regulation, impulse control, rationalization, judgement, planning etc. It is chiefly responsible for organization of behavior, speech and reasoning (Fuster, 2009). Prefrontal cortex plays a vital role in emotional regulation and governing behavior (Ongur and Price, 2000).

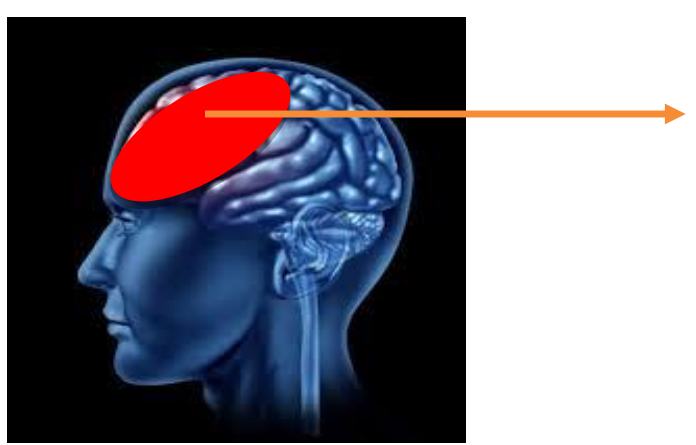

\section{PrefrontalCortex}

(logic, reasoning, analysis of consequences)

Fig. 1 Diagramatic representation of an adult brain showing fully developed Prefrontal cortex.

\section{ADOLESCENT BRAIN}

An adolescent's brain in different from an adult human brain in the sense that in it, the Prefrontal Cortex is still in its developmental stage and is not fully developed until the age of mid-twenties. During stressful situations in absence of a fully developed prefrontal cortex to think through the situation, the fully developed Limbic system, a neural system in brain activated by reward, takes precedence over other pathways of information processing. Whereas in adults the mature prefrontal cortex keeps a check on limbic system and its instincts.

Owing to this, in an adolescent the judgement, rationalization and prudence provided by prefrontal cortex have negligible influence on reward valuation, its reinforcement and emotional reactivity (Casey, Jones, \& Hare, 2008). The hyperactivity in the impulsive limbic system overrides the reflective prefrontal cortex system (Bechara, 2005). 


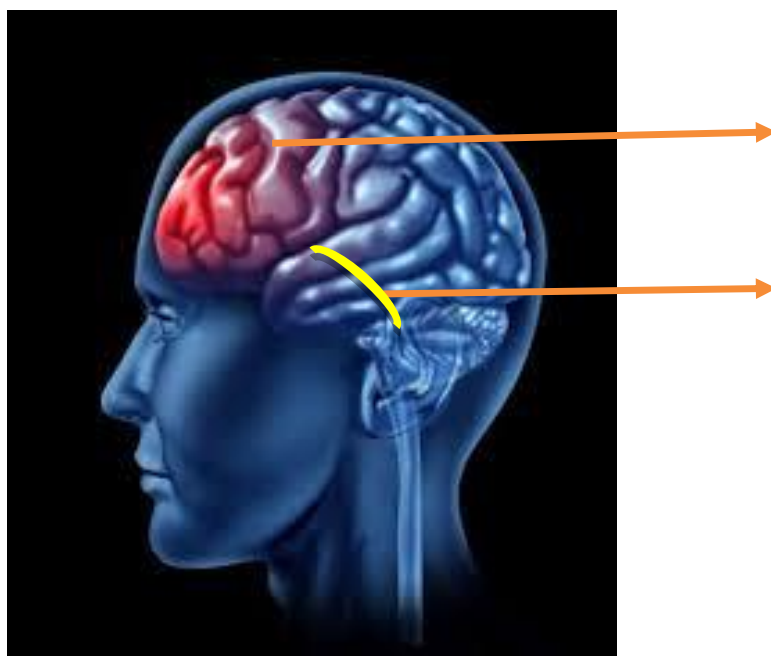

\title{
Underdeveloped Pre- Frontal Cortex
}

\author{
Highly activeLimbic Reward \\ System
}

Fig. 2 Diagrammatic representation of adolescent brain showing underdeveloped prefrontal cortex and fully developed limbic reward system

\section{COGNITIVE NEUROSCIENCE RESEARCH}

Cognitive neuroscience research has thrown great amount of light on brain's working.Major breakthroughs have been therein the understanding of Working Memory. It is basically responsible for telling us what we do with what we know.Any information through our sensory perception goes into Working Memory which is then sent to longterm memory of unlimited capacity for later retrieval.Working Memory capacity is different for different individuals. It also has different learning loops for visual, auditory and verbal material. A large Working Memory gives a learner an advantage in learning and assessment. It helps in development of certain memory strategies that result in coding information for sending it into long term memory and later retrieving from it. A large Working Memory enables an individual to device more creative memory strategies.

Conditions like stress, information overload, too much information to process, lack of previous knowledge linkages in instruction,following too many instructions, completing complex tasks, lead to what is known asCognitive Overload and causereduction in Working Memory capacity. This leads tolowering and eventually shutting down of Prefrontal Cortex functioning. Studies have established that stress weakens body's impulse control and causes production of reckless behavior (Aron, 2011). If the stress exposure becomes uncontrollable then it weakens the prefrontal cortex and contributes to substance abuse(Sinha, and $\mathrm{Li}$, 2007).

\section{IMPLICATIONS FOR ADOLESCENTS}

From above discussion we understood that stress and overload of Working Memorycan cause shutting down of prefrontal cortex and highly active limbic system to take over. During adolescence this can lead to long-lasting adverse effects(Ariza Traslaviña, G. A., de Oliveira, F. L., \& Franci, C. R.,2014). The more developed emotionally loaded limbic brain when not regulated by logical and analytical brain makes adolescence a period during which an individual is at a higher risk of harm like injury, depression, anxiety, drug use, and addiction (Kelley, Schochet, \& Landry, 2004). Research also shows that an individual's vulnerability to develop depressive disorders depends greatly on how that individual responded to stress during early life experiences (Botros, Hodgins, \& Nemeroff, 2019).

Apart from this as the Prefrontal Cortex shuts down, one or more of following conditions are likely to arise-

- Activation of Limbic Reward System

- Increased attention to perceived threat

- Academic underachievement

- Reduced attention span

- Getting distracted

- Having less control over impulsivity

- Inability to deal with social and academic tasks

- Having problems with monitoring the quality of one's own work

- Inability to evaluate consequences of decisions

- Increased anxiety

- Social, emotional and behavioural difficulties

\section{SUGGESTIONS}

In view of above presented facts, pedagogical practices based on findings of cognitive neuroscience research must be considered for inclusion and special efforts have to be made to keep the stress levels low for adolescent learners. It could mean:

1. designing reward based instruction to cater to limbic reward system in them, , 
2. content presentation through multiple channels of perception like sight, smell, hearing, touch for keeping a check on cognitive overload,

3. exercises to enhance students' Working Memory as better working memory relates to better prefrontal functioning

4. exercises like memory games, strategy building games, visual memory games, chess, picking out relevant information from random texts etc. are known to increase Working Memory. Hence, these can be linked to curricular material and included as Pedagogical tools.

5. 'one size fits all' approach must be strictly done away with and pedagogical tools must be need based.

6. a basic understanding of a learner's brain and its cognitive aspects like the role of reward system, enhancing Working Memory, providing multisensory stimulus to learners, using memory strategies, understanding learning loops etc.should be included as a topic in Teacher Training curriculum.

\section{CONCLUSION}

Hence, it can be concluded that the significance of understanding the brain of a learner cannot be ignored while designing Pedagogical tools. A true learner-centric approach needs to be based on an understanding of cognitive aspects of a learner's brain. In absence of such an understanding and lack of brain research based instructional processes, the desired learning outcomes cannot be fully achieved.

It is also very important that adolescent learners who are at a critical phase of physical, mental, emotional and physiological changes are presented with the academic content in a manner that does not increase stress, impulsivity and the feeling of fear in them.

Such practices can help reduce instances of social and behavioural difficulties in adolescents and prevent High Risk Behaviour tendencies like risky sexual behaviour, drug use and violence in them and also prevent occurrence of many mental disorders later on in life.

\section{REFERENCES}

1. Adolescence-AnAge of Opportunity. (2011). UNICEF.

https://www.unicef.org/adolescence/files/SOWC_2 011_Main_Report_EN_02092011.pdf (Retrieved on $11 / 02 / 2019$ ).

2. Ariza Traslaviña, G. A., de Oliveira, F. L., \& Franci, C. R. (2014). Early adolescent stress alters behavior and the HPA axis response in male and female adult rats: the relevance of the nature and duration of the stressor. Physiology \& behavior, 133, 178-189. https://doi.org/10.1016/j.physbeh.2014.05.031
3. Arnsten, Amy \& Raskind, Murray \& Taylor, Fletcher \& Connor, Daniel. (2015). The Effects of Stress Exposure on Prefrontal Cortex: Translating Basic Research into Successful Treatments for Post-Traumatic Stress Disorder. Neurobiology of stress. 1. 89-99. 10.1016/j.ynstr.2014.10.002.

4. Aron A. R. (2011). From reactive to proactive and selective control: developing a richer model for stopping inappropriate responses. Biological psychiatry, 69(12), e55-e68. https://doi.org/10.1016/j.biopsych.2010.07.024

5. Baddeley, A. (1986). Working Memory. Oxford: Oxford University Press.

6. Bechara A. (2005). Decision making, impulse control and loss of willpower to resist drugs: a neurocognitive neuroscience, $8(11)$, perspective. Nature 1458-1463. https://doi.org/10.1038/nn1584

7. Botros, M., Hodgins, G., \& Nemeroff, C. B. (2019). The long-lasting neurobiological scars of early-life stress: Implications for the neurobiology of depression. In Neurobiology of Depression: Road to Novel Therapeutics (pp. 111-121). Elsevier. https://doi.org/10.1016/B978-0-12813333-0.00011-1

8. Brooks, S.J. Funk, S.G. Schioth, H.B. (2017, Sep 22). The Role of Working Memory for Cognitive Control in Anorexia Nervosa vs Substance Use Disorder. Frontiers of Psychology. 8:1651. doi: 10.3389/fpsyg.2017.01651. eCollection 2017.

9. Casey, B. J., Jones, R. M., \& Hare, T. A. (2008). The adolescent brain. Annals of the New York Academy of Sciences, 1124, 111-126. https://doi.org/10.1196/annals.1440.010

10. Cowan N. (2014). Working Memory Underpins Cognitive Development, Learning, and Education. Educational psychology review, 26(2), 197-223. https://doi.org/10.1007/s10648-0139246-y

11. Fuster, J.M. (2009). Encyclopedia of Neuroscience. (L.R, Squire, Ed.) Academic Press.

12. Hadwin, J.A. Richards, H.J. (2016, Feb 2). Working Memory Training and CBT Reduces Anxiety Systems and Attentional Bias to Threat: A preliminary study. Frontiers in Psychology. doi: $10.3389 /$ fpsyg.2016.00047

13. Hindal,H. Reid, N. Badgaish, M. (2009). Working Memory, Performance and Learner Characteristics. Research in Science and Technological Education, 27(2), 187-204.

14. Holmes, J. Elizabeth, S. Gathercole. (2014). Taking Working Memory Training from the Laboratory into Schools. An International Journal of Educational Psychology, 34 (4), 440-450.

15. Jonnson, B. Wiklund-Hornquist, C. Nyroos, M. Borjesson, A. (2014, Sep). Self-reported Memory Strategies and Their Relationship to Immediate and Delayed Text Recall and Working Memory Capacity. Education Inquiry, 5 (3). DOI: 10.3402/edui.v5.22850. 
16. Kelley, A. E., Schochet, T., \& Landry, C. F. (2004). Risk taking and novelty seeking in adolescence: introduction to part I. Annals of the New York Academy of Sciences, 1021, 27-32. https://doi.org/10.1196/annals.1308.003

17. Khurana, A. Romer, D. Brodsky, N.L. Giannetta, J.M. Hurt, H. (2015, June). Stronger Working Memory Reduces, Sexual Risk Taking in Adolescents, Even After Controlling for Parental Influences. Child Development, 86 (4), 1125-1141. DOI: $10.1111 /$ cdev.12383.

18. Kim S, Lee D. Prefrontal cortex and impulsive decision making. Biol Psychiatry (2011) 69:11406. 10.1016/j.biopsych.2010.07.005

19. Klemm, W.R. (2017, March 1). The Learning Skills Cycle- A Way to Rethink Education Reform. Maryland: Rowman and Littlefield Publishing.

20. Manwani, Kamal. G. (2017, June 17). Innovative Teaching Strategies That Ensure Effective Learning. International Journal of Education and Psychological Research (IJEPR). 6(2), 93-96.

21. Ongür, D \& Price, Joseph. (2000). The Organization of Networks within the Orbital and Medial Prefrontal Cortex of Rats, Monkeys and Humans. Cerebral cortex (New York, N.Y. : 1991). 10. 206-19. 10.1093/cercor/10.3.206.

22. Santrock, John.W. (2008) . Adolescence (12th Ed,). New Delhi: Tata McGraw-Hill Publishing Company Limited.

23. Sinha, R., \& Li, C. S. (2007). Imaging stress- and cue-induced drug and alcohol craving: association with relapse and clinical implications. Drug and alcohol review, 26(1), 25-31. https://doi.org/10.1080/09595230601036960

24. Visu-Petra, L. Cheie, L. Campan, M. Scutelnicu, I. Benga, O. (2018). Identifying Early Links between Temperament, Short Term and Working Memory in Pre-schoolers. Early Child Development and Care. 180 (1), 32-45.

25. Yurgelun-Todd D. (2007). Emotional and cognitive changes during adolescence. Current opinion in neurobiology, 17(2), 251-257. https://doi.org/10.1016/j.conb.2007.03.009

26. Zins, J. E. Weissberg, R. P. Wang, M. C. \& Walberg, H.J. (Eds.). (2004). Building Academic Success on Social and Emotional Learning: What Does The Research Say? New York: Teacher's College Press. 